\title{
Serum PPAR $\gamma$ level and PPAR $\gamma$ gene polymorphism as well as severity and prognosis of brain injury in patients with arteriosclotic cerebral infarction
}

\author{
WEIMING WEI ${ }^{1 *}$, XUWEN CHEN $^{1 *}$, XUEYING LIN $^{1}$, FULAN SHAN $^{1}$, \\ SHAOPENG LIN ${ }^{2}$, QINGYU SHEN ${ }^{1}$ and LI ZHANG $^{3}$ \\ ${ }^{1}$ Department of Neurology, Zengcheng District People's Hospital of Guangzhou, Guangzhou, Guangdong 511300; \\ ${ }^{2}$ The Second Affiliated Hospital of Guangzhou Medical University, Guangzhou, Guangdong 510260; \\ ${ }^{3}$ The First Affiliated Hospital of Guangdong Pharmaceutical University, Guangzhou, Guangdong 510000, P.R. China
}

Received December 28, 2017; Accepted July 18, 2018

DOI: $10.3892 /$ etm.2018.6660

\begin{abstract}
The aim of the study was to study the serum peroxisome proliferator-activated receptor gamma (PPAR $\gamma$ ) level and PPAR $\gamma$ gene polymorphism as well as the severity and prognosis of brain injury in patients with arteriosclotic cerebral infarction (ACI). A total of 246 ACI patients presenting at the Department of Neurology of Zengcheng District People's Hospital of Guangzhou between April 2009 and July 2015 were selected as the case group, and 382 control subjects were enrolled as the control group. The hepatic and renal functions and homocysteine (Hcy) expression levels were measured. Enzyme-linked immunosorbent assay (ELISA) kit was used to detect the serum PPAR $\gamma$ levels of the ACI patients. Polymerase chain reaction-restriction fragment length polymorphism method was applied to measure the PPAR $\gamma$ gene polymorphism. The proportions of hypertension patients, diabetes patients and smoking people in the case group were significantly higher than those in the control group. The levels of cholesterol and fasting blood glucose in the case group were elevated obviously compared with those in the control group. The levels of indexes related to the hepatic function and renal function in the case group were remarkably higher than those in the control group. The serum PPAR $\gamma$ levels were increased progressively at acute stage. The distribution frequencies of PPAR $\gamma$ genotypes CC, CT and TT in the case group were higher than those in the control group; compared with that in the control group, the proportion of $\mathrm{C}$ allele in the case group
\end{abstract}

Correspondence to: Li Zhang, The First Affiliated Hospital of Guangdong Pharmaceutical University, 19 Nonglinxi Road, Guangzhou, Guangdong 510000, P.R. China

E-mail: youbang0914@163.com

*Contributed equally

Key words: cerebral infarction, arteriosclerosis, $\operatorname{PPAR} \gamma$, gene polymorphism was raised obviously, while that of $\mathrm{T}$ allele was significantly decreased. The serum PPAR $\gamma$ level has a close correlation with the PPAR $\gamma$ gene polymorphism in ACI patients, and PPAR $\gamma$ is also remarkably related to the severity of brain injury; therefore, $\operatorname{PPAR} \gamma$ has great significance in the diagnosis and treatment of cerebral infarction.

\section{Introduction}

As a type of ligand-activated transcriptional factor of nuclear receptor that is correlated with metabolic regulation, peroxisome proliferator-activated receptor gamma (PPAR $\gamma$ ) plays a vital role in controlling the storage and release of fats, glucose and lipid metabolism and energy metabolism, regulating insulin resistance, blood glucose, cell growth and differentiation and vascular inflammation reaction as well as influencing the pathological processes of vascular sclerosis (1-3). Based on the PPAR $\gamma$ expression in the brain neuron cells, PPAR $\gamma$ molecules may be released to the blood circulation when the brain tissue cells are injured $(4,5)$. However, whether the serum PPAR $\gamma$ level is associated with the severity of arteriosclotic cerebral infarction (ACI) and whether such an association is further closely related to the nucleotide polymorphism of PPAR $\gamma$ gene still need to be determined by more experiments.

As a result, this research aimed to provide a basis and direction for assessing the risk of cerebrovascular disease among the ACI patients by detecting their serum PPAR $\gamma$ level and PPAR $\gamma$ gene polymorphism in clinical practices.

\section{Materials and methods}

\section{Information}

General information. In this study, 246 ACI patients presenting at the Department of Neurology of Zengcheng District People's Hospital of Guangzhou (Guangzhou, China) from April 2009 to July 2015 were selected as the case group, and 382 subjects who were excluded of cerebral infarction through health examination were enrolled as the control group. The 246 patients in the case group were comprised of 182 males and 64 females, with an average age of $(59.7 \pm 12.1)$ years. Of 
the 382 participants in the control group, there were 226 males and 156 females, with an average age of $(56.1 \pm 10.8)$ years.

The study was approved by the Ethics Committee of Zengcheng District People's Hospital of Guangzhou and written informed consents were signed by the patients and/or guardians.

\section{Experimental methods}

General indexes. The general conditions of the participants were recorded, including age, sex, body mass index and history of hypertension, diabetes and smoking.

Blood routine tests. Fasting venous blood $(5 \mathrm{ml})$ of all the participants was withdrawn in the morning to measure the total cholesterol (TC), triglyceride (TG), low-density lipoprotein cholesterol (LDL-C) and fasting blood glucose. The levels and differences of indexes in the case group and the control group were recorded and compared.

Hepatic function measurement. The body mass indexes as well as the levels of indexes related to hepatic function, namely, alanine aminotransferase (ALT) and aspartate aminotransferase (AST), in the case group and the control group were measured and recorded, and the differences in the data were compared.

Renal function measurement. The data of indexes related to the renal function [blood urea nitrogen (BUN), serum creatinine (Scr) and uric acid (UA)] in the case group and the control group were measured, and the differences between the two groups were recorded.

Homocysteine (Hcy) level measurement. Hcy is a vital metabolic intermediate of sulfur-containing amino acid in the human body, which may be an independent risk factor for the onset of atherosclerosis and other cardiovascular diseases. The Hcy levels in both the case and control groups were measured, and the differences were compared.

PPAR $\gamma$ level measurement. Human PPAR $\gamma$ enzyme-linked immunosorbent assay (ELISA) kit was applied to detect the serum PPAR $\gamma$ levels in ACI patients three times, i.e., at acute stage (within 3-6 h), 48-72 h after ACI attack and one week after attack.

Detection of PPAR gene. The blood samples of the ACI patients were collected to extract the genomic DNA (gDNA) of peripheral blood leucocyte and detect the $P P A R \gamma$ gene. The peripheral venous blood of the research subjects was withdrawn to extract the DNA. Later, polymerase chain reaction and gel electrophoresis were performed to detect the $P P A R \gamma$ gene. The upstream primer for the PPAR $\gamma$ gene was 5'-TGAATGTGAAGCCCATTGAA-3', and the downstream primer was 5'-GAGCGGGTGAAGAAGACTCATGT-3'.

Statistical analysis. The experimental data were presented as mean \pm standard deviation (mean $\pm \mathrm{SD}$ ), and the experimental results were analyzed using Statistical Product and Service Solutions (SPSS) 17.0 software. The analysis of variance or t-test was conducted for data analysis and the post hoc test was
Table I. Comparison of general information between the case group and the control group.

\begin{tabular}{lccc}
\hline Group & $\begin{array}{c}\text { Hypertension } \\
\text { patient/case (\%) }\end{array}$ & $\begin{array}{c}\text { Diabetes } \\
\text { patient/case }(\%)\end{array}$ & $\begin{array}{c}\text { Smoking people/ } \\
\text { case (\%) }\end{array}$ \\
\hline $\begin{array}{l}\text { Case } \\
\text { group }\end{array}$ & $103(41.82 \%)$ & $66(26.83 \%)$ & $74(30.08 \%)$ \\
$\begin{array}{l}\text { Control } \\
\text { group }\end{array}$ & $82(21.47 \%)$ & $54(14.14 \%)$ & $57(14.92 \%)$ \\
\hline
\end{tabular}

LSD test. $\mathrm{P}<0.05$ suggested that the difference between the two groups was statistically significant.

\section{Results}

Measurement results of general indexes. The general conditions of the participants were recorded; it was known from Table I that in the case group, the proportion of hypertension patients was $41.82 \%$, the proportion of diabetes patients was $26.83 \%$, and that the proportion of smoking people was $30.08 \%$; the proportions of hypertension patients, diabetes patients and smoking people were $21.47,14.14$ and $14.92 \%$, respectively, in the control group. It could be seen that cerebral infarction had a certain correlation with hypertension, diabetes and smoking.

Results of blood routine tests. As shown in Fig. 1, the fasting venous blood of all the participants was withdrawn in the morning to measure the TC, TG, LDL-C and fasting blood glucose. The levels of TC, TG, LDL-C and fasting blood glucose in the case group were obviously higher than those in the control group.

Results of hepatic function measurement. The measurement results of body mass indexes as well as the levels of indexes related to the hepatic function (ALT and AST) in the case group and the control group are shown in Fig. 2. The body mass index in the case group was slightly higher than that in the control group but without significant difference. The levels of hepatic function indexes ALT and AST in the case group were significantly elevated compared with those in the control group. Thus, liver injury of the ACI patients was severe.

Results of renal function measurement. The levels of indexes related to the renal function, i.e., BUN, Scr and UA, in the case group and the control group were measured and recorded (Fig. 3). It was indicated that the levels of BUN, Scr and UA in the case group were significantly higher than those in the control group. Therefore, the kidney injury of the ACI patients was severe.

Results of Hcy level measurement. Compared with that in the control group, the Hcy level in the case group was increased significantly (Fig. 4). Patients with a high Hcy level were vulnerable to thrombosis and cardiovascular diseases; thus, there was a close relationship between the ACI patients and cardiovascular diseases. 

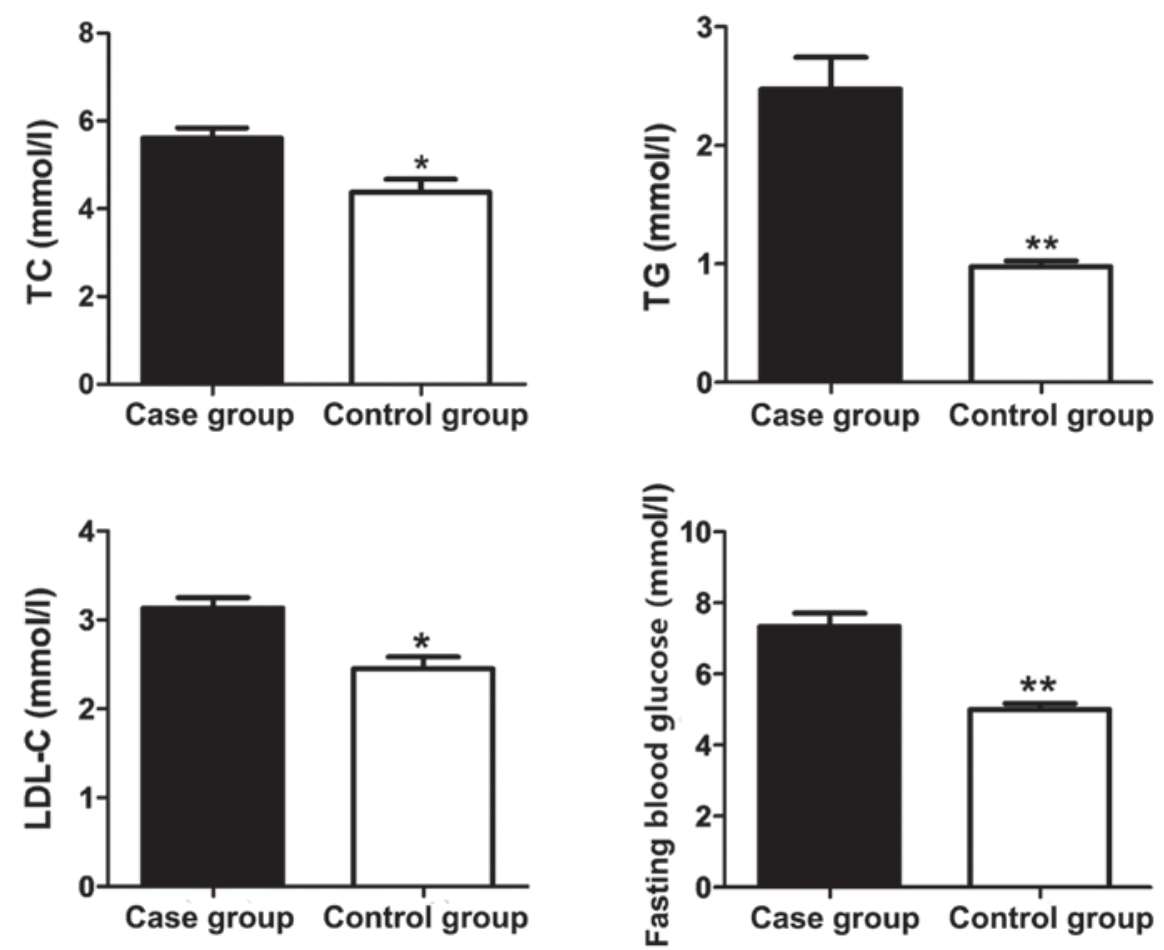

Figure 1. Results of TC, TG, LDL-C and fasting blood glucose levels in the case group and the control group. Compared with that in the case group, ${ }^{*} \mathrm{p}<0.05$, *** $\mathrm{p}<0.01$.
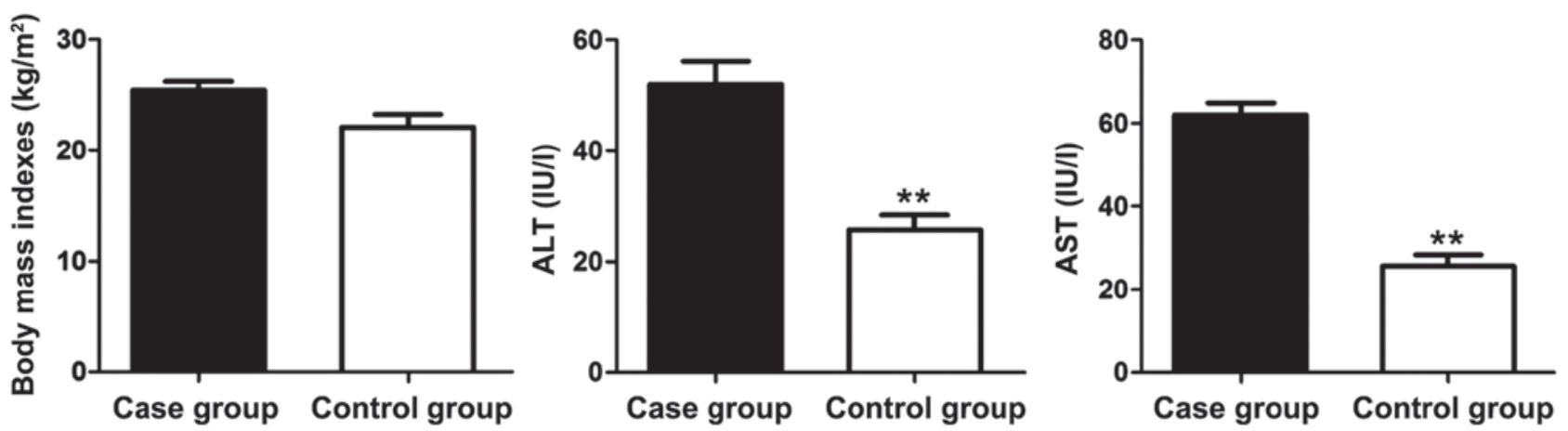

Figure 2. Results of body mass indexes as well as levels of hepatic function indexes ALT and AST in the case group and the control group. Compared with that in the case group, ${ }^{* *} \mathrm{p}<0.01$.
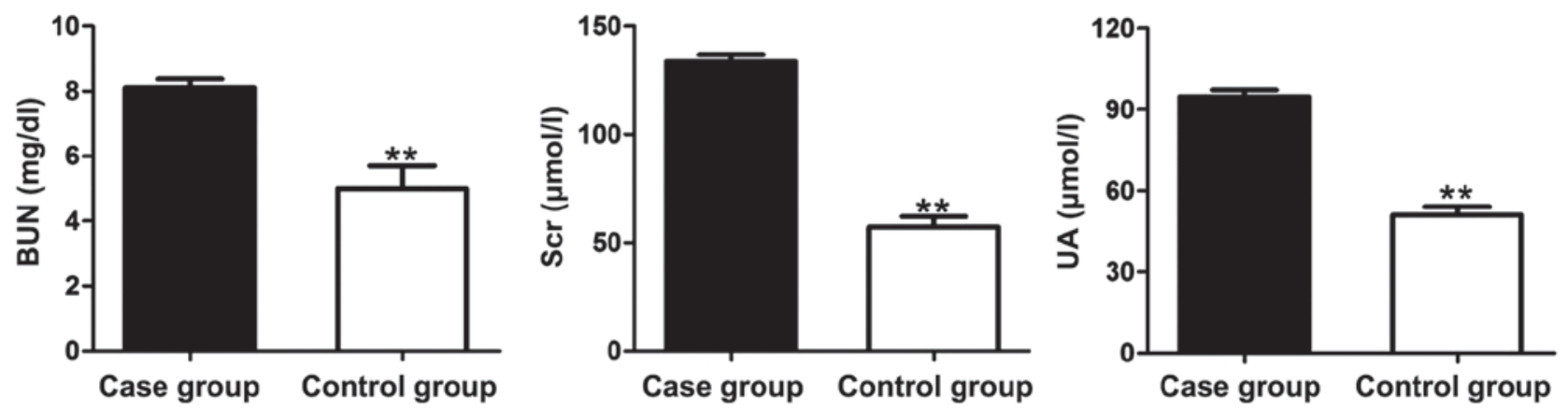

Figure 3. Results of expression levels of renal function-related indexes BUN, Scr and UA in the case group and the control group. Compared with that in the case group, ${ }^{* *} \mathrm{p}<0.01$.

Results of PPAR level measurement. Human PPAR $\gamma$ ELISA kit was used to detect the serum PPAR $\gamma$ levels of the ACI patients at acute stage (within 3-6 h), 48-72 h after ACI attack and one week after attack. As shown in Fig. 5, the serum 


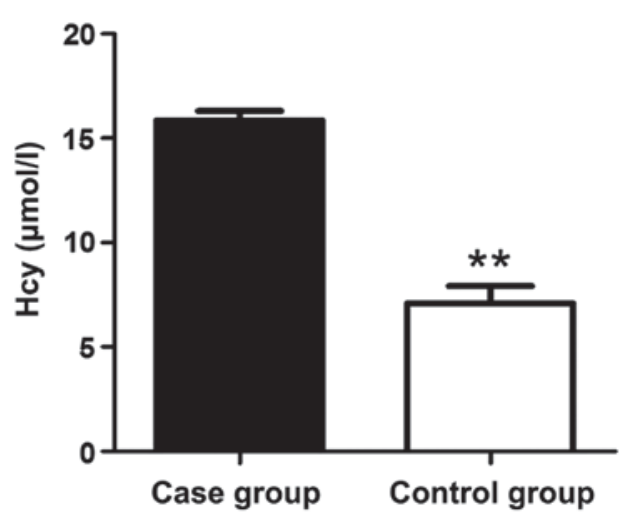

Figure 4. Expression results of Hcy levels in the case group and the control group. Compared with that in the case group, ${ }^{* *} \mathrm{p}<0.01$.

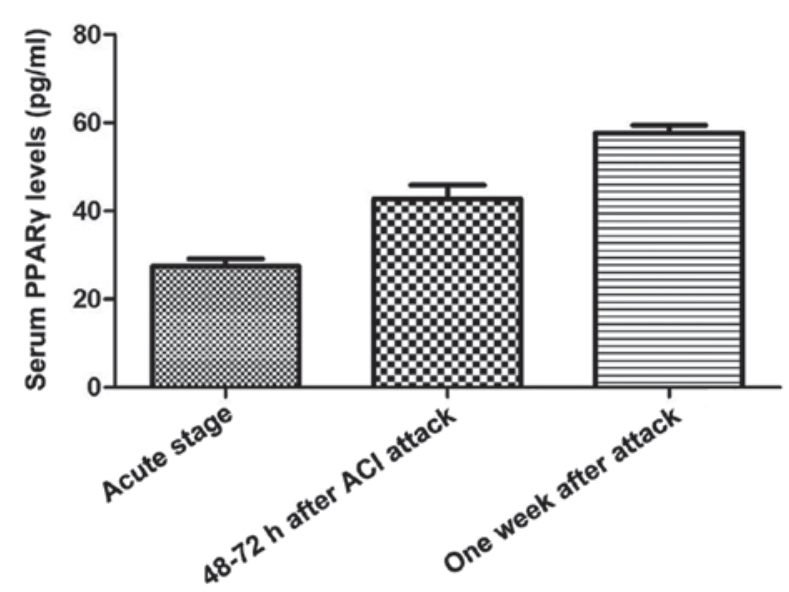

Figure 5. Results of serum PPAR $\gamma$ levels of ACI patientsat acute stage, 48-72 $\mathrm{h}$ after ACI attack and one week after attack.

PPAR $\gamma$ levels were increased progressively at the acute stage (3-6 h), 48-72 h after ACI attack and one week after attack.

Results of PPAR gene detection. The results of genotype distribution allele frequencies in the case group and the control group are shown in Table II. In the case group, the distribution frequencies of PPAR $\gamma$ genotypes $\mathrm{CC}, \mathrm{CT}$ and TT were $74.6,22.3$ and $2.6 \%$, respectively, the $\mathrm{C}$ allele frequency was $87.3 \%$, and the Tallele frequency was $14.1 \%$. In the control group, the distribution frequencies of genotypes CC, CT and TT were 61.1, 37.6 and 3.1\%, respectively, of which the $\mathrm{C}$ allele frequency was $78.6 \%$, and the T allele frequency was $20.6 \%$.

\section{Discussion}

ACI is also known as atherothrombotic brain infarction (6). It may occur in all ages, particularly in the elderly; many lifestyle habits and diseases, such as high-fat diet, diabetes and smoking, can induce and accelerate ACI (7-9). With the development of the society, improvement of living standards and huge changes in lifestyle in recent years, ACI has become a disease that poses a serious threat to both life and health, and its incidence rate is on the increase annually (10-13). However, the pathogenesis of ACI also remains unclear due to currently imperfect diagnosis and treatment of ACI. Multiple factors, including inflammation,
Table II. PPAR $\gamma$ genotypes and allele distribution in the case group and the control group.

\begin{tabular}{lccccccc}
\hline & \multicolumn{3}{c}{$\begin{array}{c}\text { Genotype } \\
\text { frequency (\%) }\end{array}$} & & & \multicolumn{2}{c}{$\begin{array}{c}\text { Diabetes } \\
\text { patient (\%) }\end{array}$} \\
\cline { 2 - 3 } \cline { 7 - 8 } Group & $\mathrm{CC}$ & $\mathrm{CT}$ & $\mathrm{TT}$ & & $\mathrm{C}$ & $\mathrm{T}$ \\
\hline Case group & $74.6 \%$ & $22.3 \%$ & $2.6 \%$ & & $87.3 \%$ & $14.1 \%$ \\
Control group & $61.1 \%$ & $37.6 \%$ & $3.1 \%$ & & $78.6 \%$ & $20.6 \%$ \\
\hline
\end{tabular}

oxidative stress and apoptosis, influence the occurrence and progression of the disease. Therefore, it is imminent to identify safe and effective ACI treatment methods $(14,15)$.

There are three types of PPAR family, namely, PPAR $\alpha$, $\operatorname{PPAR} \beta$ and PPAR $\gamma$, which have different histologic manifestations and reflect varying physiological functions (16). PPAR is praised as the 'the ultimate mystery of human health', whose amazing effects on promoting human health, preventing diseases and treating various difficult and miscellaneous diseases are discovered by more and more scientific research and clinical trials (17). The PPAR molecules in the human body are a group of nucleoprotein receptors with transcription-regulating function, which consist of the subtypes PPAR $\alpha, \operatorname{PPAR} \beta$ and PPAR $\gamma$; they are widely present in the nuclei of liver, fat, vessel wall and skeletal muscle (18). The activated PPARs can affect the manifestations of different genes in the body, act on the mechanisms of adjusting metabolism of glucose and lipid, ameliorating resistance, guarding against inflammation and preventing cell malignant transformation, and operate for a 'stable' state in the human body (19). PPAR $\gamma$ is a superfamily of nuclear receptors, which is involved in many regulation processes for cell functions and pathophysiology at the transcription level, including adipocyte differentiation, glucose and lipid metabolism, inflammatory reaction, atherosclerosis as well as cancer cell differentiation and formation; in addition to the treatment of diabetes, the PPAR $\gamma$ agonist may be applied to treat atherosclerosis, tumors and inflammatory diseases in the future (20).

In this study, $246 \mathrm{ACI}$ patients presenting at the Department of Neurology of our hospital between April 2009 and July 2015 were selected as the case group, and 382 control subjects, who were excluded of cerebral infarction through health examination, were enrolled as the control group. The general information and blood routine of the two groups were recorded. The hepatic and renal functions and Hcy expression level were measured, and ELISA was utilized to detect the serum PPAR $\gamma$ levels of the ACI patients at acute stage, 48-72 $\mathrm{h}$ after ACI attack and one week after attack. Polymerase chain reaction-restriction fragment length polymorphism method was applied to measure the PPAR $\gamma$ gene polymorphism, and the results indicated that the proportion of hypertension patients, diabetes patients and smoking people in the case group were significantly higher than those in the control group. The results of blood routine tests showed that the levels of TC, TG, LDL-C and fasting blood glucose in the case group were evidently elevated compared with those in the control group. The levels of the hepatic function-related indexes ALT and AST as well as renal function-related indexes BUN, Scr and 
UA in the case group were significantly higher than those in the control group. Moreover, compared with that in the control group, the Hcy level in the case group was increased notably. It was revealed in the ELISA results that the serum PPAR $\gamma$ levels were increased progressively at acute stage, 48-72 $\mathrm{h}$ after ACI attack and one week after attack. The distribution frequencies of PPAR $\gamma$ genotypes CC,CT and TT in the case group were higher than those in the control group. Compared with that in the control group, the proportion of $\mathrm{C}$ allele in the case group was significangtly increased, while that of $\mathrm{T}$ allele was lowered significantly. In conclusion, the serum PPAR $\gamma$ level has a close association with the PPAR $\gamma$ gene polymorphism in ACI patients, and PPAR $\gamma$ is also markedly related to the severity of brain injury. Thus, PPAR $\gamma$ can play a crucial role in the diagnosis and treatment of ACI in the future.

\section{Acknowledgements}

Not applicable.

\section{Funding}

No funding was received.

\section{Availability of data and materials}

The datasets used and/or analyzed during the current study are available from the corresponding author on reasonable request.

\section{Authors' contributions}

WW and LZ contributed to the detection of PPAR $\gamma$ gene. XC and XL collected and analyzed the general information of the patients. FS helped with routine blood test. SL and QS were responsible for Hcy level measurement. All authors read and approved the final manuscript.

\section{Ethics approval and consent to participate}

The study was approved by the Ethics Committee of Zengcheng District People's Hospital of Guangzhou (Guangzhou, China) and written informed consents were signed by the patients and/or guardians.

\section{Patient consent for publication}

Not applicable.

\section{Competing interests}

The authors declare that they have no competing interests.

\section{Authors' information}

Not applicable.

\section{References}

1. Semple RK, Chatterjee VK and O'Rahilly S: PPAR gamma and human metabolic disease. J Clin Invest 116: 581-589, 2006.
2. Forman BM, Tontonoz P, Chen J, Brun RP, Spiegelman BM and Evans RM: 15-Deoxy-delta 12, 14-prostaglandin J2 is a ligand for the adipocyte determination factor PPAR $\gamma$. Cell 83: 803-812, 1995.

3. Kliewer SA, Lenhard JM, Willson TM, Patel I, Morris DC and Lehmann JM: A prostaglandin J2 metabolite binds peroxisome proliferator-activated receptor $\gamma$ and promotes adipocyte differentiation. Cell 83: 813-819, 1995.

4. Yue Tl TL, Chen J, Bao W, Narayanan PK, Bril A, Jiang W, Lysko PG, Gu JL, Boyce R, Zimmerman DM, et al: In vivo myocardial protection from ischemia/reperfusion injury by the peroxisome proliferator-activated receptor- $\gamma$ agonist rosiglitazone. Circulation 104: 2588-2594, 2001.

5. Shimazu T, Inoue I, Araki N, Asano Y, Sawada M, Furuya D, Nagoya $\mathrm{H}$ and Greenberg JH: A peroxisome proliferatoractivated receptor- $\gamma$ agonist reduces infarct size in transient but not in permanent ischemia. Stroke 36: 353-359, 2005.

6. Sundararajan S, Gamboa JL, Victor NA, Wanderi EW, Lust WD and Landreth GE: Peroxisome proliferator-activated receptorgamma ligands reduce inflammation and infarction size in transient focal ischemia. Neuroscience 130: 685-696, 2005.

7. Lin TN, Cheung WM, Wu JS, Chen JJ, Lin H, Chen JJ, Liou JY, Shyue SK and Wu KK: 15d-prostaglandin J2 protects brain from ischemia-reperfusion injury. Arterioscler Thromb Vasc Biol 26: 481-487, 2006.

8. Chen ST, Hsu CY, Hogan EL, Maricq H and Balentine JD: A model of focal ischemic stroke in the rat: Reproducible extensive cortical infarction. Stroke 17: 738-743, 1986.

9. Lin TN, He YY, Wu G, Khan M and Hsu CY: Effect of brain edema on infarct volume in a focal cerebral ischemia model in rats. Stroke 24: 117-121, 1993

10. Tsai YS, Kim HJ, Takahashi N, Kim HS, Hagaman JR, Kim JK and Maeda N: Hypertension and abnormal fat distribution but not insulin resistance in mice with P465L PPARgamma. J Clin Invest 114: 240-249, 2004.

11. Hu X, Rea HC, Wiktorowicz JE and Perez-Polo JR: Proteomic analysis of hypoxia/ischemia-induced alteration of cortical development and dopamine neurotransmission in neonatal rat. J Proteome Res 5: 2396-2404, 2006.

12. Liu K, Mori S, Takahashi HK, Tomono Y, Wake H, Kanke T, Sato Y, Hiraga N, Adachi N, Yoshino T, et al: Anti-high mobility group box 1 monoclonal antibody ameliorates brain infarction induced by transient ischemia in rats. FASEB J 21: 3904-3916, 2007.

13. Liou JY, Ghelani D, Yeh S and Wu KK: Nonsteroidal antiinflammatory drugs induce colorectal cancer cell apoptosis by suppressing 14-3-3epsilon. Cancer Res 67: 3185-3191, 2007.

14. Kawamoto Y, Akiguchi I, Tomimoto H, Shirakashi Y, Honjo Y and Budka H: Upregulated expression of 14-3-3 proteins in astrocytes from human cerebrovascular ischemic lesions. Stroke 37: 830-835, 2006.

15. Umahara T, Uchihara T, Tsuchiya K, Nakamura A and Iwamoto T: Intranuclear localization and isoform-dependent translocation of 14-3-3 proteins in human brain with infarction. J Neurol Sci 260: 159-166, 2007.

16. Lehmann JM, Moore LB, Smith-Oliver TA, Wilkison WO, Willson TM and Kliewer SA: An antidiabetic thiazolidinedione is a high affinity ligand for peroxisome proliferator-activated receptor $\gamma$ (PPAR $\gamma$ ). J Biol Chem 270: 12953-12956, 1995.

17. Ricote M, Li AC, Willson TM, Kelly CJ and Glass CK: The peroxisome proliferator-activated receptor- $\gamma$ is a negative regulator of macrophage activation. Nature 391: 79-82, 1998.

18. Jiang C, Ting AT and Seed B: PPAR- $\gamma$ agonists inhibit production of monocyte inflammatory cytokines. Nature 391: 82-86, 1998.

19. Chawla A, Barak Y, Nagy L, Liao D, Tontonoz P and Evans RM: PPAR- $\gamma$ dependent and independent effects on macrophage-gene expression in lipid metabolism and inflammation. Nat Med 7: 48-52, 2001.

20. Welch JS, Ricote M, Akiyama TE, Gonzalez FJ and Glass CK: PPARgamma and PPARdelta negatively regulate specific subsets of lipopolysaccharide and IFN- $\gamma$ target genes in macrophages. Proc Natl Acad Sci USA 100: 6712-6717, 2003.

(i) $\ominus$ This work is licensed under a Creative Commons Attribution-NonCommercial-NoDerivatives 4.0 International (CC BY-NC-ND 4.0) License. 